\section{Removal of a Mango Seed from the Esophagus Using a Specially Designed Retrieval Device}

An unusual case of a mango seed impacted in the lower esophagus, which was removed using a specially designed retrieval device, is reported here.

A 62-year-old man was admitted with history of absolute dysphagia and pain in the chest of two days' duration following accidental ingestion of a mango seed while eating the fruit. Upper gastrointestinal endoscopy showed a mango seed impacted at the lower end of the esophagus (Figure 1). Since the seed was large, a retrieval snare was devised. A pusher tube used for inserting 7-Fr biliary stents (Wilson-Cook Medical, Inc., Winston-Salem, NC) was cut to shorten it, and a polypectomy snare wire was threaded through it (Figure 2). The assembly was passed through the biopsy channel of the endoscope, and was opened fully so as to encircle the seed. It was then closed tightly on the seed, and the whole assembly, along with the seed and the endoscope, was removed in one go. A repeat endoscopy did not reveal any abnormality in the esophagus or the cardia of the stomach. The patient did not have any complication, and was discharged.

Most ingested foreign bodies pass spontaneously, but $10-20 \%$ need to be removed endoscopically, and about $1 \%$ require surgery $(1,2)$. The patient described here had a unique foreign body in the form of a mango seed. In a review (3) and a study (4) of large numbers of foreign bodies observed in the upper gastrointestinal tract, no case of mango seed was noted. Mango seed impaction may occur in this part of the world because the majority of people here suck the juice and pulp of the mango by directly placing their mouth over the fruit while simultaneously pressing it with hands from all sides.

The retrieving device designed in this case is very simple. A nasobiliary drainage catheter or any tubing that can be inserted via the biopsy channel of the endoscope, and which can accept a snare wire, can be used as external tubing instead of the pusher tube used in this case. It is hoped that such a device could be useful in removing other large impacted foreign bodies in the esophagus, preventing surgical interventions.

\section{S. P. Misra, M. Dwivedi}

Dept. of Gastroenterology, M. L. N. Medical College, Allahabad, India

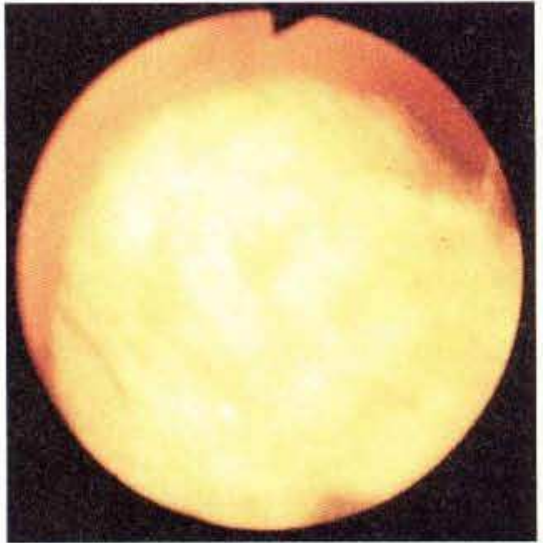

Figure 1: Endoscopic view of the impacted mango seed in the lowe esophagus.

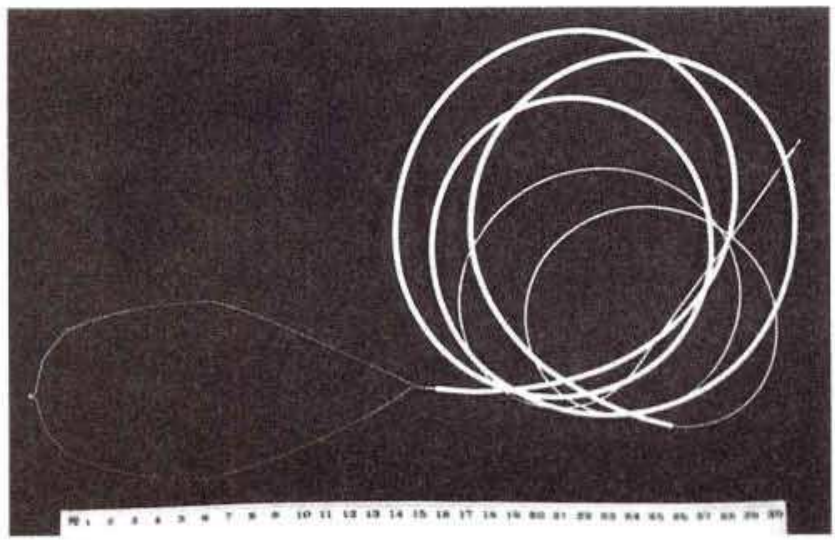

Figure 2: The retrieval device used to remove the mango seed.

\section{References}

1. Schwartz GF, Polsky HS. Ingested foreign bodies of the gastrointestinal tract. Am Surg 1976; 42: 236-8.

2. Perelman H. Toothpick perforation of the gastrointestinal tract. J Abdom Surg 1962; 4: 51-3.

3. Ginsberg GG. Management of ingested foreign objects and food bolus impactions. Gastrointest Endose 1995; 41: 33-8.

4. Webb WA. Management of foreign bodies of the upper gastrointestinal tract: update. Gastrointest Endosc 1995; 41: 3951.

Corresponding Author

S. P. Misra, M.D.

Dept. of Gastroenterology

M. L. N. Medical College

Allahabad 211011

India

Fax: $+91-532-604418$ 